\title{
Inflammation in the pathogenesis of microvascular complications in diabetes
}

\section{Dung V. Nguyen, Lynn C. Shaw and Maria B. Grant*}

Department of Pharmacology and Therapeutics, University of Florida, College of Medicine, Gainesville, FL, USA

\section{Edited by:}

Maria Lopes-Virella, Medical

University of South Carolina, USA

\section{Reviewed by:}

Licio A. Velloso, University of

Campinas, Brazil

Charles Roberts, Oregon National

Primate Research Center, USA

${ }^{*}$ Correspondence:

Maria B. Grant, Department of Pharmacology and Therapeutics, University of Florida, College of Medicine, P.O. Box 100267,

Gainesville, FL 32610-0267, USA.

e-mail: grantma@ufl.edu
Diabetes and hyperglycemia create a proinflammatory microenvironment that progresses to microvascular complications such as nephropathy, retinopathy, and neuropathy. Dietinduced insulin resistance is a potential initiator of this change in type 2 diabetes which can increase adipokines and generate a chronic low-grade inflammatory state. Advanced glycation end-products and its receptor, glycation end-products AGE receptor axis, reactive oxygen species, and hypoxia can also interact to worsen complications. Numerous efforts have gained way to understanding the mechanisms of these modulators and attenuation of the inflammatory response, however, effective treatments have still not emerged. The complexity of inflammatory signaling may suggest a need for multi-targeted therapy. This review presents recent findings aimed at new treatment strategies.

\section{Keywords: inflammation, diabetes mellitus, microvascular complications, oxidative stress, advanced glycation} end-products, inflammatory cytokines

\section{INTRODUCTION}

Inflammation plays an essential role in the progression of diabetic microvascular complications. Proinflammatory cytokines C-reactive protein, tumor necrosis factor (TNF)- $\alpha$, and interleukin (IL)-6 all demonstrate increased expression in diabetes (Peters et al., 1986; Ford, 1999; Festa et al., 2000; Müller et al., 2002; Temelkova-Kurktschiev et al., 2002). In chronic hyperglycemia, cytokines infiltrate vascular tissues and inhibit function and repair. Obesity is a major risk factor for diabetes and can induce inflammation by Toll-like receptor (TLR) activation to recruit proinflammatory cytokines and chemokines (Kwon et al., 2012). With the onset of diabetes, adipokines such as TNF- $\alpha$ and IL-6 may contribute to insulin resistance (Rajala and Scherer, 2003; Suganami et al., 2005). Adiponectin is initially upregulated to increase glucose uptake, and nitric oxide (NO) production; however, continued obesity may reduce adiponectin leading to complications observed in type 2 diabetes (T2D; Berg et al., 2001; Matsuzawa, 2005). Obesity is also associated with hyperlipidemia with elevated levels of cholesterol and triglycerides which may contribute to inflammation and diabetic retinopathy (DR; Dodson et al., 1981). The Fenofibrate Intervention and Event Lowering in Diabetes (FIELD) study found no relationship between serum lipid levels and DR (Keech et al., 2007; Chew et al., 2010). Fenofibrate is known to lower lipid levels, but it can also activate peroxisome proliferator-activated receptors (PPARs) and suppress inflammation by inhibiting nuclear factor kappa B (NF-кB; Tomizawa et al., 2011). As metabolic syndrome and inflammation persist, oxidative stress, hypoxia, and advanced glycation end-products (AGEs)/AGE receptor (RAGE) converge to exacerbate the problem (Brownlee, 2005; Vincent et al., 2011). A schematic summarizing the pathogenesis of diabetic microvascular complications is presented (Figure 1). The focus of this review is to overview the most recent findings relevant to treating nephropathy, retinopathy, and neuropathy.

\section{DIABETIC NEPHROPATHY}

Diabetic nephropathy (DN) is the leading cause of end-stage renal disease (Nilsson et al., 2008). DN results in basement membrane thickening, expansion of the mesangium, reduced filtration, albuminuria, and ultimately renal failure (Graves and Kayal, 2008). Inflammatory cells can accumulate in glomeruli and interstitium to worsen DN (Lim and Tesch, 2012). Recent findings have identified a few key receptors involved in renal protection. Studies targeting these pathways along with other known mediators of inflammation have revealed the importance of inflammation in worsening DN.

Peroxisome proliferator-activated receptors are activated in response to fatty acids and regulate lipid and glucose homeostasis (Wahli and Michalik, 2012). In the kidney, PPAR $\gamma$ expression has been found in medullary collecting ducts, pelvic urothelium, and isolated glomeruli and cultured mesangial cells (Iwashima et al., 1999; Yang et al., 1999; Asano et al., 2000; Kume et al., 2008). Pioglitazone, a PPAR $\gamma$ agonist, increased anti-oxidant activity and reduced inflammation in hyperoxaluric rats (Taguchi et al., 2012). This suggests activation of PPAR $\gamma$ may have renoprotective functions. Similarly, the same agonist treated in T2D diabetic rats showed improved insulin resistance, glycemic control, and lipid profile while reducing inflammation by reducing macrophage infiltration and NF- $\mathrm{KB}$ expression (Ko et al., 2008).

Resveratrol (trans-3,4',5-trihydroxyestilbene, RSV) is a polyphenolic compound found in grapes and other plants providing anti-oxidant effects (Chang et al., 2011). RSV improved renal function and reduced oxidative stress in type 1 diabetic (T1D) rats (Sharma et al., 2006; Dhaunsi and Bitar, 2012). Similarly, RSV treatment showed significant decreases in superoxide anion and protein carbonyl oxidative stress markers (Chang et al., 2011). RSV was shown to reduce renal lipotoxicity and mesangial cell glucotoxicity in diabetic mice mediated through activation of PPAR $\gamma$ co-activator $1 \alpha$ (Kim et al., 2012). In another study, 


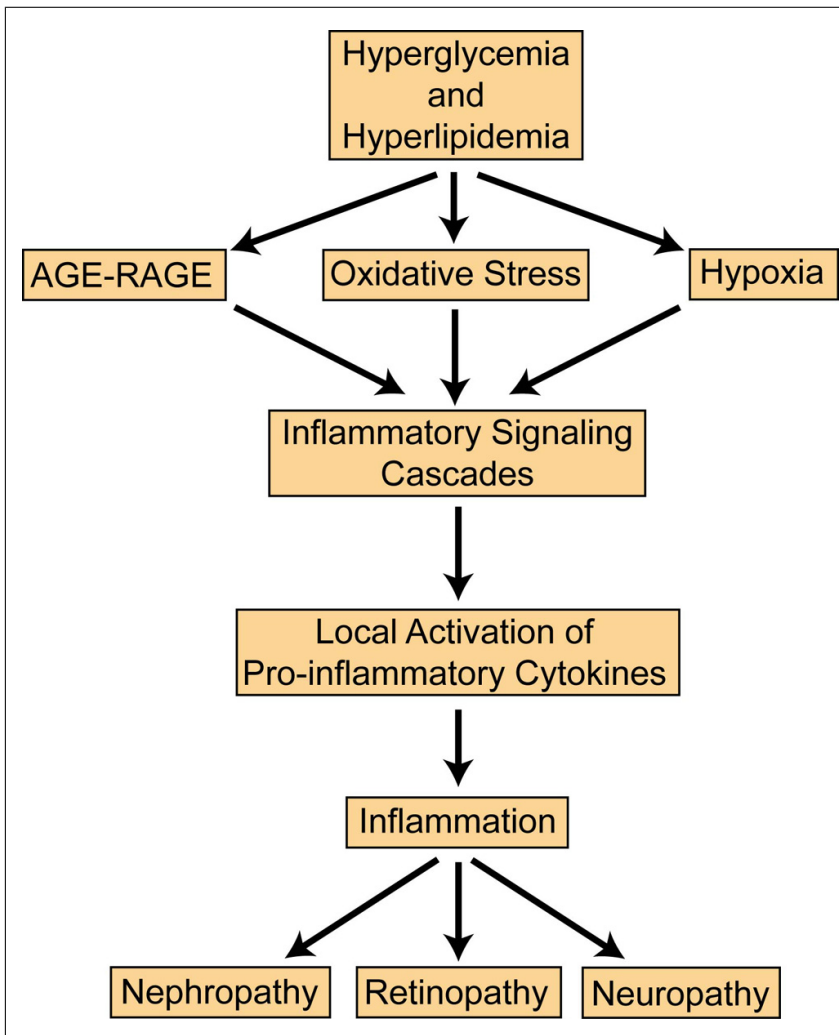

FIGURE 1 | General pathway in the progression of diabetic microvascular complications.

RSV reduced IL-1 $\beta$ in streptozotocin (STZ)-diabetic rat kidneys, but there was a significant increase in TNF- $\alpha$ and IL-6 levels independent of NF- $\kappa \mathrm{B}$ activation, suggesting RSV has both stimulatory and inhibitory effects on cytokines simultaneously and achieving the optimal dose may be critical to establishing efficacy (Chang et al., 2011).

$\mathrm{F} c \gamma$ receptors $(\mathrm{Fc} \gamma \mathrm{R})$ are present in leukocytes, glomerular, and mesangial cells (Gómez-Guerrero et al., 1994, 2002; Radeke et al., 2002). Fc $\gamma$ R can bind to immunoglobulin G (IgG). Circulating oxidized LDL-containing immune complexes (oxLDL-IC) are increased in diabetes stimulate synthesis of IgGs in addition to other proinflammatory cytokines such as IL-1 $\beta$, IL-6, IL-18, and TNF- $\alpha$ in Mono Mac 6 cells and primary human macrophages (Saad etal., 2006; Abdelsamie etal., 2011). Increased oxLDLICs also increases matrix production in mesenchymal mesangial cells through activation of Fc $\gamma$ RI and Fc $\gamma$ RIII to increase collagen IV production in nephropathy (Abdelsamie et al., 2011). Attenuating Fc $\gamma \mathrm{R}$ activity may reduce the development of a proinflammatory environment and enhanced matrix production. A genetic defect in $\mathrm{Fc} \gamma \mathrm{R}$ attenuated diabetic renal injury based on histological analyses and reduced leukocyte accumulation in glomeruli and interstitium (Lopez-Parra et al., 2012). There was also a reduction in intracellular superoxide generation in vivo and oxidative response to oxLDL-ICs in vitro (Lopez-Parra et al., 2012).

Dietary lipids preceding diabetes have been shown to upregulate proinflammatory cytokines and TLR transcriptional levels along with downregulation of transcripts involved in glucose metabolism in epididymal and mesenteric white adipose tissue (Kwon et al., 2012). TLR are innate immune receptors that have been implicated in T1D, T2D, and its associated complications (de Kleijn and Pasterkamp, 2003; Park et al., 2004; Rudofsky et al., 2004; Wen et al., 2004; Lang et al., 2005). In DN, TLR4 expression was increased in $\mathrm{T} 2 \mathrm{D}$ and uremic patients and in mouse mesangial cells, suggesting its role in monocyte recruitment (Kaur et al., 2012; Yang et al., 2012). Studies confirmed increased TLR4 activation when cells were incubated with high glucose (Kaur et al., 2012). Monocytes displaying CD14 ${ }^{+} \mathrm{CD} 16^{+}$surface markers in the kidney can associate with TLR and activate NF- $\kappa \mathrm{B}$, and STAT expression to further promote a proinflammatory microenvironment (Yang et al., 2012). Therapeutic targets correcting dysregulated TLR signaling may therefore be an important target against inflammation and complications within the kidney.

Advanced glycation end-product production is widely associated with diabetic microvascular complications. Recent studies showed little benefit using benfotiamine, a lipophilic thiaminederivative that activates transketolase to reduce AGE precursors (Babaei-Jadidi et al., 2003; Karachalias et al., 2010). Benfotiamine had no effect in decreasing existing plasma AGE or increasing AGE excretion (Alkhalaf et al., 2012). Similarly, evaluation of benfotiamine in cerebral cortex of STZ-induced diabetic rats showed little effect on reducing AGEs and TNF- $\alpha$, however, it slightly attenuated oxidative stress (Wu and Ren, 2006). Despite the outcome, this approach remains active and a recent proposal has aimed at modifying the delivery to have dual targets instead of singular targeting. Using a nanoparticle shell, both AGE and RAGE inhibitors will be encased within the shell to suppress both axes and redundancy not addressed with a single therapy (Zhou et al., 2012). The exterior of the shell will contain RAGE analogs, which can also provide specificity to AGEs and delivery of therapeutics (Zhou et al., 2012). This dual therapy approach is still in its infancy, but it may have potential benefits if pursued to target both receptors and its ligands.

Current standard treatment of DN targets the reninangiotensin system (RAS) through usage of angiotensin converting enzyme (ACE) inhibitors to limit systemic blood pressure to control intraglomerular pressure (Bonegio and Susztak, 2012). Upstream targeting may further decrease RAS activity. Aliskiren, a direct renin inhibitor, has been recently evaluated in DN. Treatment using aliskiren showed a significant reduction in TNF- $\alpha$ and transforming growth factor (TGF)- $\beta$ (Gandhi et al., 2012). Some studies have shown that TGF- $\beta$ may have a role in influencing renal growth and inflammation as well as fibrosis and renal dysfunction (Ziyadeh et al., 2000; Phillips and Steadman, 2002).

\section{DIABETIC RETINOPATHY}

Diabetic retinopathy is one of the leading causes of blindness in adults of working age adults. Background DR is characterized by ischemic injury which creates a hypoxic environment in ocular tissues. Hypoxia has been shown to induce microglia activation and recruitment to ischemic sites in retinas (Kielczewski etal., 2011). Vascular injury in background DR and proliferative DR (PDR) increases proinflammatory cytokines which 
can promote leukostasis and vascular endothelial growth factor (VEGF) mediated permeability in the retinal vasculature (Chistiakov, 2011).

The retinal pigment epithelium (RPE) provides functional barriers for the exchange of nutrients to photoreceptor cells. Under hyperglycemia, microglia and macrophages accumulate in the RPE in Goto Kakizaki rats (Omri et al., 2011). Increases in transepithelial pores compromise tight junction integrity and allow materials to enter the choroidal space (Omri et al., 2011). Presence of inflammation can reduce transepithelial resistance (TER) and impact ion gradient generation between membrane transporters and tight junctions (Rizzolo et al., 2011). TNF- $\alpha$ exposure to human RPE cells showed decreased TER (Peng et al., 2012). GPR109A is a G protein-coupled receptor (GPCR) present in RPE that is upregulated in diabetic mouse and human retina (Gambhir et al., 2012). GPR109A has immunomodulatory effects in adipose tissue and progression of atherosclerosis (Digby et al., 2010; Montecucco et al., 2010; Lukasova et al., 2011). Two ligands of GPR109A, niacin and $\beta$-hydroxybutyrate, was shown to suppress IL- 6 and chemokine ligand-2 (CCL2) induced by TNF- $\alpha$ (Gambhir et al., 2012). Additional studies should explore potential value of modulating GPR109A activity with its ligands to suppress inflammation in the retina of those discussed as well as other proinflammatory cytokines (Gambhir et al., 2012).

$\beta$-catenin is a downstream effector of the Wnt pathway and is found to be increased in several diabetic rodent models and in humans (Chen et al., 2009). Increased $\beta$-catenin may be due to sustained Wnt signaling where it can also activate NF-кB to induce inflammation (Dale, 1998; Yamashina et al., 2006; Yan et al., 2008). DR is characterized by hypoxia and oxidative stress, which contribute to Wnt activation. Blockage of Wnt led to reduced inflammation through decreased ICAM-1 in the retina (Chen et al., 2009). Mab2F1, a monoclonal antibody targeting Wnt coreceptor LDL receptor-related protein 6 resulted in reduced retinal vascular leakage, inflammation, and attenuation of leukostasis (Lee et al., 2012).

Comparing cytokine levels of peripheral blood in diabetic patients revealed that levels of IL-22 expressed by T-helper (Th) 22 was significantly increased compared to controls, however, the differences were not significant between NPDR, PDR, and in diabetic patients without DR (Chen et al., 2012). IL-22 levels were also positively correlated with duration of diabetes (Chen et al., 2012). TNF- $\alpha$ has been shown to be increased in serum of diabetic patients. The results from this study suggest a potential role of Th22 expressing IL-22 levels in the pathogenesis of diabetic complications.

Increased RAGE levels and its ligand S100B are found in rat diabetic retinas and also found in cultured Müller glial cells exposed to high glucose (Limb et al., 2002; Zong et al., 2010). S100B has been shown induce inflammatory cytokines such as TNF- $\alpha$ and vascular CAM (VCAM)-1 in human microvascular endothelial cells (Valencia et al., 2004). Similarly, Müller glial cells treated with exogenous S100B showed increased levels of TNF- $\alpha$, IL-6, IL-8, VEGF, and CCL2 (Zong et al., 2010). Treatment of S100B in cells showed a dose-dependent activation of mitogen-activated protein kinase pathway (MAPK) (Zong et al., 2010). In vivo studies should assess the relevant concentrations of $\mathrm{S} 100 \mathrm{~B}$ in pathogenesis of DR.
The RAS plays a vital role in regulating many physiological processes of the vascular system. Elevated levels of renin, prorenin, and Angiotensin II (Ang II) are found in patients with DR (Wilkinson-Berka, 2008). In PDR, prorenin and its receptor $[(\mathrm{P}) \mathrm{RR}]$ are upregulated in retinal endothelial cells (Kanda et al., 2012). Increased (P)RR, prorenin, and activated prorenin were found in human vitreous fluid which can promote inflammatory angiogenesis in the eye (Satofuka et al., 2008; Kanda et al., 2012). (P)RR can activate extracellular signal-regulated kinases (ERK) and induce inflammatory responses in the eye (Kanda et al., 2012). Blockage of (P)RR reduced ERK activity and decreased diabetes-induced retinal inflammation (Satofuka et al., 2012).

Downstream effectors also have important functions in DR. Ang II, a product of ACE, activates the $\mathrm{AT}_{1}$ receptor to induce vasoconstriction, proliferation, fibrosis, and inflammation. The protective arm of the RAS involves ACE2, which produces Ang-(1-7). As a vasodilator peptide with anti-hypertensive, antihypertrophic, anti-fibrotic, and anti-thrombotic functions (3), Ang-(1-7) stimulates NO production by activating endothelial NO synthase (eNOS) in an Akt-dependent manner and decreases ROS production by attenuating NADPH oxidase. Ang-(1-7) mediates its effects by activating the GPCR, the Mas receptor (Sampaio etal., 2007; Benter etal., 2008). Chronic Ang-(1-7) treatment preserves endothelial function in rat models of myocardial ischemia and in-stent restenosis (Loot et al., 2002; Langeveld et al., 2005). Treatment with ACE2 or Ang-(1-7) corrected diabetic defects in therapeutic angiogenesis (Oudit et al., 2010; Figure 2). Intraocular administration of adeno-associated virus expressing ACE2/Ang-(1-7) significantly reduced CD45 ${ }^{+}$macrophages, $\mathrm{CD}_{1} \mathrm{~b}^{+}$microglial cells, and oxidative damage in mice (Verma et al., 2012). Targeting both upstream and downstream components of the RAS axis may provide synergistic effects in treating microvascular complications.

\section{DIABETIC NEUROPATHY}

Diabetic neuropathy (DNO) is the most common complication of diabetes, where population-based studies have indicated more than half of the patients with either T1D or T2D develop DNO, and as much as $30 \%$ of those manifestations are painful (Harati, 2007; Ramos et al., 2007; Farmer et al., 2012). Recent reviews have emphasized the importance of targeting oxidative stress and inflammation in the treatment of DNO (Vincent et al., 2011; Farmer et al., 2012).

Tumor necrosis factor- $\alpha$ has been implicated in contributing to insulin resistance in obesity due to its increased expression in adipose tissue. Obese mice with a TNF- $\alpha^{-/-}$mutation displayed improved insulin sensitivity and lowered circulating fatty acids, improving obesity-induced glucose tolerance (Uysal et al., 1997). Increased plasma TNF- $\alpha$ and macrophages are also associated with the progression of DNO, suggesting continued expression of these cytokines contribute to diabetic microvascular complications (Purwata, 2011). Similar experiments evaluating TNF- $\alpha$ null mice showed that they are less susceptible to developing diabetic complications (Gao et al., 2007). Targeting TNF- $\alpha$ through pharmacological means can potentially reverse the deleterious effects in DNO. Infliximab, a monoclonal anti-TNF- $\alpha$ antibody approved for treatment of autoimmune diseases such as rheumatoid arthritis 


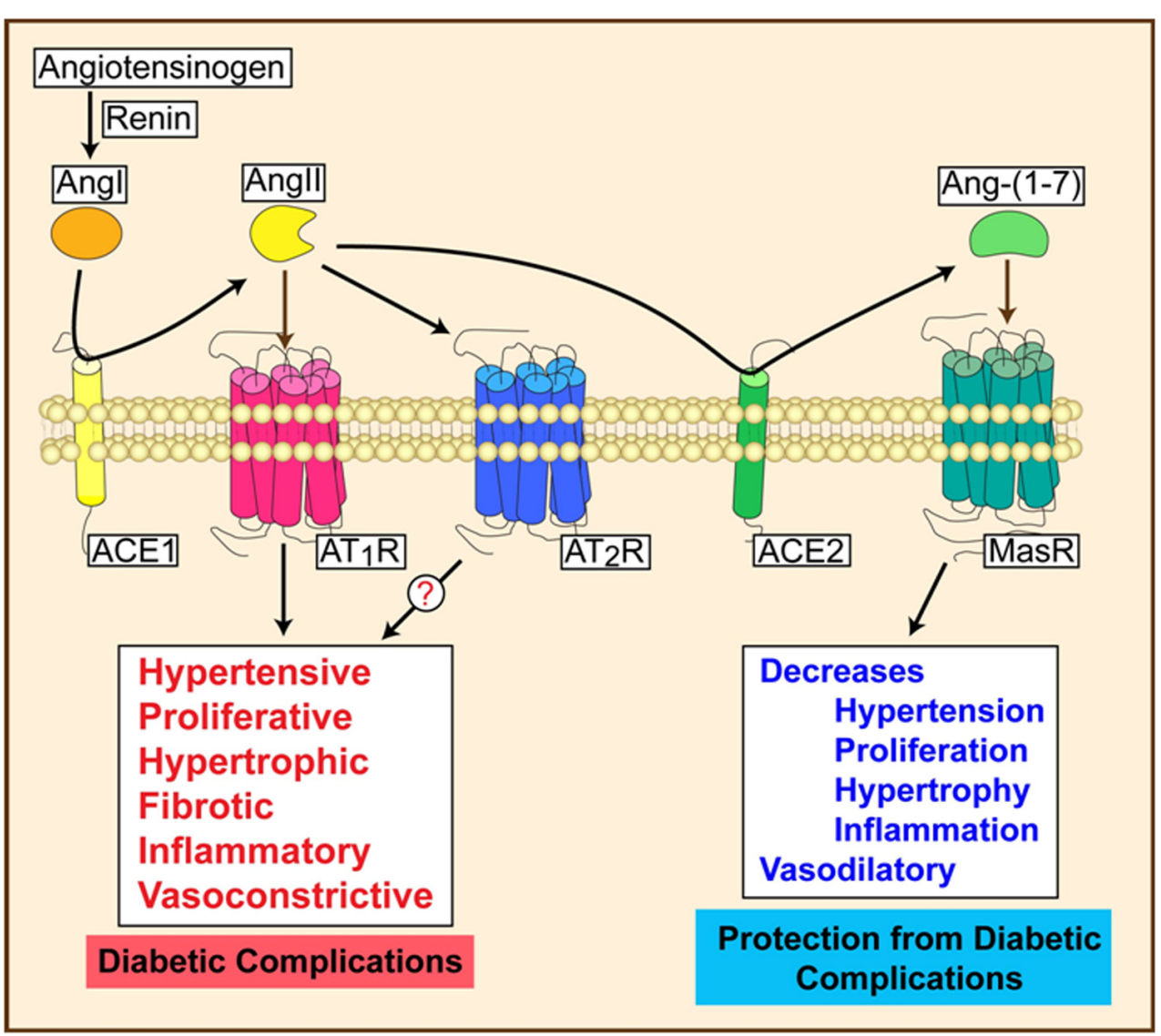

FIGURE 2 | Activation of RAS can lead to progressive or protective effects depending on the signaling mechanisms.

and psoriasis has been explored (Lin et al., 2008). Administration of infliximab into T1D mice showed significant improvement in neural function comparable to non-diabetic controls (Yamakawa et al., 2011).

Tumor necrosis factor- $\alpha$ can also influence AGE/RAGE activity making it a relevant target in DNO. In the progression of DNO, RAGE expression was increased in diabetic peripheral nerves and dorsal root ganglia (DRG; Toth et al., 2008). Mice models deficient in RAGE attenuated the structural and electrophysiological changes in peripheral nerves and DRG after prolonged diabetes of 5 months and also reduced NF- $\kappa \mathrm{B}$ and protein kinase $\mathrm{C}$ activation (Toth et al., 2008). NF-кB can induce apoptosis, cell cycle, and plasticity, neurogenesis, and differentiation in the central nervous system (Foehr et al., 2000; Kumar et al., 2004; Fraser, 2006). RSV has been shown to inhibit NF- $\kappa$ B activity and TNF- $\alpha$, IL6, and cyclooxygenase-2 levels (Kumar and Sharma, 2010). BAY 11-7082, an inhibitor of kappa B (ІкB) phosphorylation, downregulated $\mathrm{NF}-\kappa \mathrm{B}$ and led to improved sensory response, motor nerve conduction velocity, and nerve blood flow (Kumar et al., 2012). Similarly, there was a significant reduction in the oxidative stress marker, malondialdehyde, IL- 6 , and TNF- $\alpha$ levels (Kumar et al., 2012). While IL-6 is generally regarded as proinflammatory, its role in DNO is still unclear since IL-6 administration may have neurotrophic effects (Cotter et al., 2010).
Bradykinin B1 receptor (B1R) of the kallikrein-kinin system has been shown to be upregulated in response to increases of oxidative stress in diabetes (Dias et al., 2010). In another study, minocycline has been shown to exhibit anti-inflammatory and anti-oxidant effects by inhibiting microglia activation (Pabreja et al., 2011). Inhibition of microglia activation in STZ-diabetic rats using either fluorocitrate or minocycline reduced B1R expression along with IL- $1 \beta$ and TNF- $\alpha$ proinflammatory cytokines in spinal dorsal horn (Talbot et al., 2010). Microglia inhibitors may have an effect on thermal hyperalgesia and allodynia which support a role of B1R in pain neuropathy (Talbot et al., 2010). Antagonists to B1R showed a reversal of allodynia in STZ-diabetic rats, suggesting the mediation of early DNO due to inflammation (Talbot et al., 2010). However, in Akita mice, loss of B1R and bradykinin B2 receptor (B2R) appears to exacerbate nephropathy and neuropathy, suggesting that its activation in this diabetes model may be protective (Kakoki et al., 2010). Further studies should assess the role of B1R in different animal models of diabetes.

Angiopoietin-1 (Ang-1) has been demonstrated to have benefits against vascular leakage and endothelial cell survival (Cho etal., 2004). Variants have been developed to improve on solubility and potency (Cho et al., 2004). Matrilin-1-Ang-1 (MAT-Ang-1) has been demonstrated to have anti-inflammatory protection against cytokines IL- $1 \alpha$, IL- $1 \beta$, IL-6, and TNF- $\alpha$ 
in sepsis (Alfieri et al., 2012). Another variant, cartilage oligomeric matrix protein (COMP)-Ang-1, has been hypothesized to improve regeneration of nerve fibers and endoneural microvessels in leptin-deficient obese (ob/ob) mice, a model for T2D (Kosacka et al., 2012). COMP-Ang-1 treatment was capable of reducing macrophage infiltration and T-cell number in sciatic nerves of ob/ob mice by 45 and 47\%, respectively (Kosacka et al., 2012). Upstream effectors of Ang-1 have also recently been explored. Thymosin $\beta 4$ improved diabetes-induced vascular dysfunction in sciatic nerve, nerve function and can mediate this through upregulation of Ang-1 in diabetic mice (Wang et al., 2012). Regulators of Ang-1 may therefore have benefits against neural and vascular dysfunction.

\section{CONCLUSION}

The worldwide increase in prevalence of obesity and dietinduced insulin resistance increases the need to reduce chronic

\section{REFERENCES}

Abdelsamie, S. A., Li, Y., Huang, Y., Lee, M. H., Klein, R. L., Virella, G., et al. (2011). Oxidized LDL immune complexes stimulate collagen IV production in mesangial cells via Fc gamma receptors I and III. Clin. Immunol. $139,258-266$.

Alfieri, A., Watson, J. J., Kammerer, R. A., Tasab, M., Progias, P., Reeves, K., et al. (2012). Angiopoietin-1 variant reduces LPS-induced microvascular dysfunction in a murine model of sepsis. Crit. Care 16, R182.

Alkhalaf, A., Kleefstra, N., Groenier, K. H., Bilo, H. J. G., Gans, R. O. B., Heeringa, P., et al. (2012). Effect of benfotiamine on advanced glycation endproducts and markers of endothelial dysfunction and inflammation in diabetic nephropathy. PLoS ONE 7:e40427. doi: 10.1371/journal.pone.0040427

Asano, T., Wakisaka, M., Yoshinari, M., Iino, K., Sonoki, K., Iwase, M., et al. (2000). Peroxisome proliferator-activated receptor gammal (PPARgammal) expresses in rat mesangial cells and PPARgamma agonists modulate its differentiation. Biochim. Biophys. Acta 1497, 148-154.

Babaei-Jadidi, R., Karachalias, N., Ahmed, N., Battah, S., and Thornalley, P. J. (2003). Prevention of incipient diabetic nephropathy by high-dose thiamine and benfotiamine. Diabetes 52, 2110-2120.

Benter, I. F., Yousif, M. H., Dhaunsi, G. S., Kaur, J., Chappell, M. C., and Diz, D. I. (2008). Angiotensin-(1-7) prevents activation of NADPH oxidase and renal vascular dysfunction in diabetic hypertensive rats. Am. J. Nephrol. 28, 25-33.

Berg, A. H., Combs, T. P., Du, X., Brownlee, M., and Scherer, P. E.
(2001). The adipocyte-secreted protein Acrp30 enhances hepatic insulin action. Nat. Med. 7, 947-953.

Bonegio, R., and Susztak, K. (2012). Notch signaling in diabetic nephropathy. Exp. Cell Res. 318, 986-992.

Brownlee, M. (2005). The pathobiology of diabetic complications: a unifying mechanism. Diabetes 54, 1615-1625.

Chang, C. C., Chang, C. Y., Wu, Y. T., Huang, J. P., Yen, T. H., and Hung, L. M. (2011). Resveratrol retards progression of diabetic nephropathy through modulations of oxidative stress, proinflammatory cytokines, and AMP-activated protein kinase. J. Biomed. Sci. 18, 47.

Chen, H., Wen, F., Zhang, X., and $\mathrm{Su}, \mathrm{S}$. B. (2012). Expression of T-helper-associated cytokines in patients with type 2 diabetes mellitus with retinopathy. Mol. Vis. 18, 219-226.

Chen, Y., Hu, Y., Zhou, T., Zhou, K. K., Mott, R., Wu, M., et al. (2009). Activation of the Wnt pathway plays a pathogenic role in diabetic retinopathy in humans and animal models. Am. J. Pathol. 175, 2676-2685.

Chew, E. Y., Ambrosius, W. T., Davis, M. D., Danis, R. P., Gangaputra, S., Greven, C. M., et al. (2010). Effects of medical therapies on retinopathy progression in type 2 diabetes. $N$. Engl. J. Med. 363, 233-244.

Chistiakov, D. A. (2011). Diabetic retinopathy: pathogenic mechanisms and current treatments. Diabetes Metab. Syndr. 5, 165-172.

Cho, C. H., Kammerer, R. A., Lee, H. J., Steinmetz, M. O., Ryu, Y. S., Lee, S. H., et al. (2004). COMP-Angl: a designed angiopoietin-1 variant with nonleaky angiogenic activity. Proc. Natl. Acad. Sci. U.S.A. 101, 55475552 .

inflammation. Diabetic microvascular complications progress due to inflammation which originates from multiple pathways and mechanisms. This complexity warrants the need for effective therapies that target more than one signaling cascade. Inhibition of both inflammatory cytokines and their activators/regulators may provide additional coverage to treating nephropathy, retinopathy, and neuropathy. Similarly, this can be combined and optimized with anti-oxidant and AGE/RAGE therapies to mitigate compensatory mechanisms. As further studies emerge to address current limitations, improved therapies targeting diabetic microvascular complications may ultimately transition from treating the pathology to prevention.

\section{ACKNOWLEDGMENTS}

This work was supported by National Institutes of Health, R01 EY007739, R01 EY12601, and R01 DK090730.

Cotter, M. A., Gibson, T. M., Nangle, M. R., and Cameron, N. E. (2010). Effects of interleukin-6 treatment on neurovascular function, nerve perfusion and vascular endothelium in diabetic rats. Diabetes Obes. Metab. 12, 689-699.

Dale, T. C. (1998). Signal transduction by the Wnt family of ligands. Biochem. J. 329(Pt 2), 209-223.

de Kleijn, D., and Pasterkamp, G. (2003). Toll-like Receptors in Cardiovascular Diseases. Cardiovasc. Res. 60, 58-67.

Dhaunsi, G. S., and Bitar, M. S. (2012). Antioxidants attenuate diabetes-induced activation of peroxisomal functions in the rat kidney. $J$. Biomed. Sci. 11, 566-570.

Dias, J. P., Talbot, S., Sénécal, J., Carayon, P., and Couture, R. (2010). Kinin B1 receptor enhances the oxidative stress in a rat model of insulin resistance: outcome in hypertension, allodynia and metabolic complications. PLoS ONE 5:e12622. doi: 10.1371/journal.pone.0012622

Digby, J. E., McNeill, E., Dyar, O. J., Lam, V., Greaves, D. R., and Choudhury, R. P. (2010). Antiinflammatory effects of nicotinic acid in adipocytes demonstrated by suppression of fractalkine, RANTES, and MCP-1 and upregulation of adiponectin. Atherosclerosis 209, 89-95.

Dodson, P. M., Galton, D. J., and Winder, A. F. (1981). Retinal vascular abnormalities in the hyperlipidaemias. Trans. Ophthalmol. Soc. U.K. 101, 17-21.

Farmer, K. L., Li, C., and Dobrowsky, R. T. (2012). Diabetic peripheral neuropathy: should a chaperone accompany our therapeutic approach? Pharmacol. Rev. 64 880-900.
Festa, A., D’Agostino, R. Jr., Howard, G., Mykkänen, L., Tracy, R. P., and Haffner, S. M. (2000). Chronic subclinical inflammation as part of the insulin resistance syndrome: the Insulin Resistance Atherosclerosis Study (IRAS). Circulation 102, 42-47.

Foehr, E. D., Lin, X., O'Mahony, A., Geleziunas, R., Bradshaw, R. A., and Greene, W. C. (2000). NF-kappa B signaling promotes both cell survival and neurite process formation in nerve growth factor-stimulated PC12 cells. J. Neurosci. 20, 7556-7563.

Ford, E. S. (1999). Body mass index, diabetes, and C-reactive protein among U.S. adults. Diabetes Care 22, 19711977.

Fraser, C. C. (2006). Exploring the positive and negative consequences of NF-kappaB inhibition for the treatment of human disease. Cell Cycle 5, 1160-1163.

Gambhir, D., Ananth, S., VeerananKarmegam, R., Elangovan, S., Hester, S., Jennings, E., et al. (2012). GPR109A as an anti-inflammatory receptor in retinal pigment epithelial cells and its relevance to diabetic retinopathy. Invest. Ophthalmol. Vis. Sci. 53, 2208-2217.

Gandhi, S., Srinivasan, B., and Akarte, A. S. (2012). Aliskiren improves insulin resistance and ameliorates diabetic renal vascular complications in STZ-induced diabetic rats. J. Renin Angiotensin Aldosterone Syst. doi: $\quad 10.1177 / 1470320312452766$ [Epub ahead of print].

Gao, X., Belmadani, S., Picchi, A., Xu, X., Potter, B. J., Tewari-Singh, N., et al. (2007). Tumor necrosis factoralpha induces endothelial dysfunction in Lepr(db) mice. Circulation $115,245-254$.

Gómez-Guerrero, C., López-Armada, M. J., González, E., and Egido, J. 
(1994). Soluble IgA and IgG aggregates are catabolized by cultured rat mesangial cells and induce production of TNF-alpha and IL-6, and proliferation. J. Immunol. 153, 52475255.

Gómez-Guerrero, C., López-Franco, O., Suzuki, Y., Sanjuán, G., HernándezVargas, P., Blanco, J., et al. (2002). Nitric oxide production in renal cells by immune complexes: role of kinases and nuclear factor-kappaB. Kidney Int. 62, 2022-2034.

Graves, D. T., and Kayal, R. A. (2008). Diabetic complications and dysregulated innate immunity. Front. Biosci.13:1227-1239.

Harati, Y. (2007). Diabetic neuropathies: unanswered questions. Neurol. Clin. 25, 303-317.

Iwashima, Y., Eto, M., Horiuchi, S. and Sano, H. (1999). Advanced glycation end product-induced peroxisome proliferator-activated receptor gamma gene expression in the cultured mesangial cells. Biochem. Biophys. Res. Commun. 264 , 441-448.

Kakoki, M., Sullivan, K. A., Backus, C., Hayes, J. M., Oh, S. S., Hua, K., et al. (2010). Lack of both bradykinin B1 and B2 receptors enhances nephropathy, neuropathy, and bone mineral loss in Akita diabetic mice. Proc. Natl. Acad. Sci. U.S.A. 107, 10190 10195.

Kanda, A., Noda, K., Saito, W., and Ishida, S. (2012). (Pro)renin receptor is associated with angiogenic activity in proliferative diabetic retinopathy. Diabetologia 55, 3104-3113.

Karachalias, N., Babaei-Jadidi, R., Rabbani, N., and Thornalley, P. J. (2010). Increased protein damage in renal glomeruli, retina, nerve, plasma and urine and its prevention by thiamine and benfotiamine therapy in a rat model of diabetes. Diabetologia 53, 1506-1516.

Kaur, H., Chien, A., and Jialal, I. (2012). Hyperglycemia induces Toll like receptor 4 expression and activity in mouse mesangial cells: relevance to diabetic nephropathy. Am. J. Physiol. Renal Physiol. 303, F1145F1150.

Keech, A. C., Mitchell, P., Summanen, P. A., O'Day, J., Davis, T. M., Moffitt, M. S., et al. (2007). Effect of fenofibrate on the need for laser treatment for diabetic retinopathy (FIELD study): a randomised controlled trial. Lancet 370, 1687-1697.

Kielczewski, J. L., Hu, P., Shaw, L. C., Li Calzi, S., Mames, R. N., Gardiner, T. A., etal. (2011). Novel protective properties of IGFBP-3 result in enhanced pericyte ensheathment, reduced microglial activation, increased microglial apoptosis, and neuronal protection after ischemic retinal injury. Am. J. Pathol. 178, 1517-1528.

Kim, M. Y., Lim, J. H., Youn, H. H., Hong, Y. A., Yang, K. S., Park, H. S., et al. (2012). Resveratrol prevents renal lipotoxicity and inhibits mesangial cell glucotoxicity in a manner dependent on the AMPK-SIRT1PGCl $\alpha$ axis in $\mathrm{db} / \mathrm{db}$ mice. Diabetologia doi: 10.1007/s00125-0122747-2 [Epub ahead of print].

Ko, G. J., Kang, Y. S., Han, S. Y., Lee, M. H., Song, H. K., Han, K. H., et al. (2008). Pioglitazone attenuates diabetic nephropathy through an anti-inflammatory mechanism in type 2 diabetic rats. Nephrol. Dial. Transplant. 23, 2750-2760.

Kosacka, J., Nowicki, M., Klöting, N., Kern, M., Stumvoll, M., Bechmann, I., et al. (2012). COMP-angiopoietin1 recovers molecular biomarkers of neuropathy and improves vascularisation in sciatic nerve of $\mathrm{ob} / \mathrm{ob}$ mice. PLoS ONE 7:e32881. doi 10.1371/journal.pone.0032881

Kumar, A., Negi, G., and Sharma, S. S. (2012). Suppression of NF- $\kappa$ B and NF- $\kappa$ B regulated oxidative stress and neuroinflammation by BAY 11-7082 ( $\mathrm{\kappa} \kappa \mathrm{B}$ phosphorylation inhibitor) in experimental diabetic neuropathy. Biochimie 94, 1158-1165.

Kumar, A., and Sharma, S. S. (2010). NF-kappaB inhibitory action of resveratrol: a probable mechanism of neuroprotection in experimental diabetic neuropathy. Biochem. Biophys. Res. Commun. 394, 360-365.

Kumar, A., Takada, Y., Boriek, A. M., and Aggarwal, B. B. (2004). Nuclear factor-kappaB: its role in health and disease. J. Mol. Med. 82, 434-448.

Kume, S., Uzu, T., Isshiki, K. and Koya, D. (2008). Peroxisome proliferator-activated receptors in diabetic nephropathy. PPAR Res. 2008, 879523.

Kwon, E. Y., Shin, S. K., Cho, Y. Y., Jung, U. J., Kim, E., Park, T., et al. (2012). Time-course microarrays reveal early activation of the immune transcriptome and adipokine dysregulation leads to fibrosis in visceral adipose depots during diet-induced obesity. BMC Genomics 13:450. doi: 10.1186/1471-2164-13-450

Lang, K. S., Recher, M., Junt, T., Navarini, A. A., Harris, N. L., Freigang, S., et al. (2005). Toll-like receptor engagement converts T-cell autoreactivity into overt autoimmune disease. Nat. Med. 11, 138-145. Langeveld, B., van Gilst, W. H., Tio, R. A., Zijlstra, F., and Roks, A. J. (2005).
Angiotensin-(1-7) attenuates neointimal formation after stent implantation in the rat. Hypertension 45 138-141.

Lee, K., Hu, Y., Ding, L., Chen, Y., Takahashi, Y., and Mott, R. (2012). Therapeutic potential of a monoclonal antibody blocking the wnt pathway in diabetic retinopathy. Diabetes 61, 2948-2957.

Lim, A. K., and Tesch, G. H. (2012). Inflammation in diabetic nephropathy. Mediators Inflamm. 146154.

Limb, G. A., Salt, T. E., Munro, P. M., Moss, S. E., and Khaw, P. T. (2002). In vitro characterization of a spontaneously immortalized human Müller cell line (MIO-M1). Invest. Ophthalmol. Vis. Sci. 43, 864-869.

Lin, J., Ziring, D., Desai, S., Kim, S., Wong, M., and Korin, Y., (2008). TNFalpha blockade in human diseases: an overview of efficacy and safety. Clin. Immunol. 126, 13-30.

Loot, A. E., Roks, A. J., Henning, R. H., Tio, R. A., Suurmeijer, A. J., Boomsma, F., et al. (2002). Angiotensin-(1-7) attenuates the development of heart failure after myocardial infarction in rats. Circulation 105, 1548-1550.

Lopez-Parra, V., Mallavia, B., LopezFranco, O., Ortiz-Muñoz, G., Oguiza, A., Recio, C., et al. (2012). $\mathrm{Fc} \gamma$ receptor deficiency attenuates diabetic nephropathy. J. Am. Soc. Nephrol. 23, 1518-1527.

Lukasova, M., Malaval, C., Gille, A., Kero, J., and Offermanns, S. (2011) Nicotinic acid inhibits progression of atherosclerosis in mice through its receptor GPR109A expressed by immune cells. J. Clin. Invest. 121 1163-1173.

Matsuzawa, Y. (2005). Adiponectin: identification, physiology and clinical relevance in metabolic and vascular disease. Atheroscler. Suppl. 6, 7-14.

Montecucco, F., Quercioli, A., Dallegri, F., Viviani, G. L., and Mach, F. (2010). New evidence for nicotinic acid treatment to reduce atherosclerosis. Expert Rev. Cardiovasc. Ther. 8 , 1457-1467.

Müller, S., Martin, S., Koenig, W. Hanifi-Moghaddam, P., Rathmann, W., Haastert, B., et al. (2002). Impaired glucose tolerance is associated with increased serum concentrations of interleukin 6 and co-regulated acute-phase proteins but not TNF-alpha or its receptors. Diabetologia 45, 805-812.

Nilsson, J., Bengtsson, E., Fredrikson, G. N., and Björkbacka, H. (2008). Inflammation and immunity in diabetic vascular complications. Curr. Opin. Lipidol. 19, 519-524.
Omri, S., Behar-Cohen, F., de Kozak, Y., Sennlaub, F., Verissimo, L. M., Jonet, L., et al. (2011). Microglia/macrophages migrate through retinal epithelium barrier by a transcellular route in diabetic retinopathy: role of $\mathrm{PKC} \zeta$ in the Goto Kakizaki rat model. Am. J. Pathol. 179, 942-953.

Oudit, G. Y., Liu, G. C., Zhong, J., Basu, R., Chow, F. L., Zhou, J., et al. (2010). Human recombinant ACE2 reduces the progression of diabetic nephropathy. Diabetes 59, 529-538.

Pabreja, K., Dua, K., Sharma, S., Padi, S. S., and Kulkarni, S. K. (2011). Minocycline attenuates the development of diabetic neuropathic pain: possible anti-inflammatory and antioxidant mechanisms. Eur. J. Pharmacol. 661, 15-21.

Park, Y., Park, S., Yoo, E., Kim, D., and Shin, H. (2004). Association of the polymorphism for Toll-like receptor 2 with type 1 diabetes susceptibility. Ann. N. Y. Acad. Sci. 1037, 170-174.

Peng, S., Gan, G., Rao, V. S., Adelman, R. A., and Rizzolo, L. J. (2012). Effects of proinflammatory cytokines on the claudin-19 rich tight junctions of human retinal pigment epithelium. Invest. Ophthalmol. Vis. Sci. 53, 5016-5028.

Peters, M. A., Burke, J. M., Clowry, M., Abrams, G. W., and Williams, G. A. (1986). Development of traction retinal detachments following intravitreal injections of retinal Muller and pigment epithelial cells. Graefes Arch. Clin. Exp. Ophthalmol. 224, 554-563. Phillips, A. O., and Steadman, R. (2002). Diabetic nephropathy: the central role of renal proximal tubular cells in tubulointerstitial injury. Histol. Histopathol. 17, 247-252.

Purwata, T. E. (2011). High TNF-alpha plasma levels and macrophages iNOS and TNF-alpha expression as risk factors for painful diabetic neuropathy. J. Pain Res. 4, 169-175.

Radeke, H. H., Janssen-Graalfs, I., Sowa, E. N., Chouchakova, N., Skokowa, J., Löscher, F., et al. (2002). Opposite regulation of type II and III receptors for immunoglobulin $\mathrm{G}$ in mouse glomerular mesangial cells and in the induction of anti-glomerular basement membrane (GBM) nephritis. J. Biol. Chem. 277, 27535-27544.

Rajala, M. W., and Scherer, P. E. (2003).Minireview: the adipocyte-at the crossroads of energy homeostasis, inflammation, and atherosclerosis. Endocrinology 144, 3765-3773.

Ramos, K. M., Jiang, Y., Svensson, C. I., and Calcutt, N. A. (2007). Pathogenesis of spinally mediated hyperalgesia in diabetes. Diabetes 56, 1569-1576. 
Rizzolo, L. J., Peng, S., Luo, Y., and Xiao, W. (2011). Integration of tight junctions and claudins with the barrier functions of the retinal pigment epithelium. Prog. Retin. Eye Res. 30, 296-323.

Rudofsky, G. Jr., Reismann, P., Witte, S., Humpert, P. M., Isermann, B., Chavakis, T., et al. (2004). Asp299Gly and Thr399Ile genotypes of the TLR4 gene are associated with a reduced prevalence of diabetic neuropathy in patients with type 2 diabetes. Diabetes Care 27, 179-183.

Saad, A. F., Virella, G., Chassereau, C., Boackle, R. J., and LopesVirella, M. F., (2006). OxLDL immune complexes activate complement and induce cytokine production by MonoMac 6 cells and human macrophages. J. Lipid Res. 47, 19751983.

Sampaio, W. O., Souza dos Santos, R. A., Faria-Silva, R., da Mata Machado, L. T., Schiffrin, E. L., and Touyz, R. M. (2007). Angiotensin-(1-7) through receptor Mas mediates endothelial nitric oxide synthase activation via Akt-dependent pathways. Hypertension 49, 185-192.

Satofuka, S., Ichihara, A., Nagai, N., Noda, K., Ozawa, Y., Fukamizu, A., et al. (2008). (Pro)renin receptor promotes choroidal neovascularization by activating its signal transduction and tissue renin-angiotensin system. Am. J. Pathol. 173, 1911-1918.

Satofuka, S., Kanda, A., and Ishida, S. (2012). Receptor-associated prorenin system in the pathogenesis of retinal diseases. Front. Biosci. 4, 1449-1460.

Sharma, S., Anjaneyulu, M., Kulkarni, S. K., and Chopra, K. (2006). Resveratrol, a polyphenolic phytoalexin, attenuates diabetic nephropathy in rats. Pharmacology 76, 69-75.

Suganami, T., Nishida, J., and Ogawa, Y. (2005). A paracrine loop between adipocytes and macrophages aggravates inflammatory changes: role of free fatty acids and tumor necrosis factor alpha. Arterioscler. Thromb. Vasc. Biol. 25, 2062-2068.

Taguchi, K., Okada, A., Yasui, T. Kobayashi, T., Ando, R., and Tozawa, K. (2012). Pioglitazone, a peroxisome proliferator activated receptor $\gamma$ agonist, decreases renal crystal deposition, oxidative stress and inflammation in hyperoxaluric rats. J. Urol. 188, 1002-1011.

Talbot, S., Chahmi, E., Dias, J. P. and Couture, R. (2010). Key role for spinal dorsal horn microglial kinin B1 receptor in early diabetic pain neuropathy. J. Neuroinflammation 7,36 .

Temelkova-Kurktschiev, T., Henkel, E., Koehler, C., Karrei, K., and Hanefeld, M. (2002). Subclinical inflammation in newly detected Type II diabetes and impaired glucose tolerance. Diabetologia 45, 151.

Tomizawa, A., Hattori, Y., Inoue, T., Hattori, S., and Kasai, K. (2011). Fenofibrate suppresses microvascular inflammation and apoptosis through adenosine monophosphate-activated protein kinase activation. Metab. Clin. Exp. 60, 513-522.

Toth, C., Rong, L. L., Yang, C., Martinez, J., Song, F., Ramji, N., et al. (2008) Receptor for advanced glycation end products (RAGEs) and experimental diabetic neuropathy. Diabetes 57, 1002-1017.

Uysal, K. T., Wiesbrock, S. M., Marino, M. W., and Hotamisligil, G. S. (1997). Protection from obesityinduced insulin resistance in mice lacking TNF-alpha function. Nature 389, 610-614.

Valencia, J. V., Mone, M., Koehne, C., Rediske, J., and Hughes, T. E. (2004) Binding of receptor for advanced glycation end products (RAGE) ligands is not sufficient to induce inflammatory signals: lack of activity of endotoxin-free albumin-derived advanced glycation end products. Diabetologia 47, 844-852.

Verma, A., Shan, Z., Lei, B., Yuan, L., Liu, X., Nakagawa, T., et al. (2012). ACE2 and Ang-(1-7) confer protection against development of diabetic retinopathy. Mol. Ther. 20 28-36.

Vincent, A. M., Callaghan, B. C., Smith, A. L., and Feldman, E. L. (2011) Diabetic neuropathy: cellular mechanisms as therapeutic targets. Nat. Rev. Neurol. 7, 573-583.
Wahli, W., and Michalik, L. (2012) PPARs at the crossroads of lipid signaling and inflammation. Trends Endocrinol. Metab. 23, 51-63.

Wang, L., Chopp, M., Szalad, A., Liu, Z., Lu, M., Zhang, L., et al. (2012). Thymosin $\beta 4$ promotes the recovery of peripheral neuropathy in type II diabetic mice. Neurobiol. Dis. 48, 546-555.

Wen, L., Peng, J., Li, Z., and Wong, F. S. (2004). The effect of innate immunity on autoimmune diabetes and the expression of Toll-like receptors on pancreatic islets. J. Immunol. 172, 3173-3180.

Wilkinson-Berka, J. L. (2008). Prorenin and the (pro)renin receptor in ocular pathology. Am. J. Pathol. 173, 1591-1594.

Wu, S., and Ren, J. (2006). Benfotiamine alleviates diabetes-induced cerebral oxidative damage independent of advanced glycation end-product, tissue factor and TNF-alpha. Neurosci. Lett. 394, 158-162.

Yamakawa, I., Kojima, H., Terashima, T., Katagi, M., Oi, J., Urabe, H., et al. (2011). Inactivation of TNF- $\alpha$ ameliorates diabetic neuropathy in mice. Am. J. Physiol. Endocrinol. Metab. 301, E844-E852.

Yamashina, K., Yamamoto, H., Chayama, K., Nakajima, K., and Kikuchi, A. (2006). Suppression of STAT3 activity by Duplin, which is a negative regulator of the Wnt signal. J. Biochem. 139, 305-314.

Yan, S., Zhou, C., Zhang, W., Zhang, G., Zhao, X., Yang, S., et al. (2008). beta-Catenin/TCF pathway upregulates STAT3 expression in human esophageal squamous cell carcinoma. Cancer Lett. 271, 85-97.

Yang, M., Gan, H., Shen, Q., Tang, W., Du, X., and Chen, D. (2012). Proinflammatory CD14+CD16+ monocytes are associated with microinflammation in patients with type 2 diabetes mellitus and diabetic nephropathy uremia. Inflammation 35, 388-396.

Yang, T., Michele, D. E., Park, J., Smart, A. M., Lin, Z., Brosius, F. C. III, et al. (1999). Expression of peroxisomal proliferator-activated receptors and retinoid $\mathrm{X}$ receptors in the kidney. Am. J. Physiol. 277, F966-F973.

Zhou, X., Wang, B., Zhu, L., and Hao, S. (2012). A novel improved therapy strategy for diabetic nephropathy: targeting AGEs. Organogenesis 8 , 18-21.

Ziyadeh, F. N., Hoffman, B. B., Han, D. C., Iglesias-De La Cruz, M. C., Hong, S. W., Isono, M., et al. (2000). Long-term prevention of renal insufficiency, excess matrix gene expression, and glomerular mesangial matrix expansion by treatment with monoclonal antitransforming growth factor-beta antibody in $\mathrm{db} / \mathrm{db}$ diabetic mice. Proc. Natl. Acad. Sci. U.S.A. 97, 8015-8020.

Zong, H., Ward, M., Madden, A., Yong, P. H., Limb, G. A., Curtis, T. M., et al. (2010). Hyperglycaemiainduced pro-inflammatory responses by retinal Müller glia are regulated by the receptor for advanced glycation end-products (RAGE). Diabetologia 53, 2656-2666.

Conflict of Interest Statement: The authors declare that the research was conducted in the absence of any commercial or financial relationships that could be construed as a potential conflict of interest.

Received: 26 September 2012; accepted: 05 December 2012; published online: 21 December 2012

Citation: Nguyen DV, Shaw LC and Grant MB (2012) Inflammation in the pathogenesis of microvascular complications in diabetes. Front. Endocrin. 3:170. doi: 10.3389/fendo.2012.00170

This article was submitted to Frontiers in Systems and Translational Endocrinology, a specialty of Frontiers in Endocrinology.

Copyright (c) 2012 Nguyen, Shaw and Grant. This is an open-access article distributed under the terms of the Creative Commons Attribution License, which permits use, distribution and reproduction in other forums, provided the original authors and source are credited and subject to any copyright notices concerning any third-party graphics etc. 